[Postprint] Please cite as: López C, Ishizaka A, GAHPSort: a new group multi-criteria decision method for sorting a large number of the cloud-based ERP solutions, Computers in Industry, 92, 12-24, 2017

\title{
GAHPSort: a new group multi-criteria decision method for sorting a large number of the cloud-based ERP solutions
}

\author{
Cristina López ${ }^{1}$ and Alessio Ishizaka \\ ${ }^{1}$ University Pablo of Olavide, Faculty of Business. Pedro R. Campomanes Building, Road Utrera, km. 1 - 41013 \\ Seville, Spain, E-mail: clopvar@upo.es \\ ${ }^{2}$ University of Portsmouth, Portsmouth Business School. Richmond Building, Portland Street, Portsmouth PO1 3DE, \\ United Kingdom, E-mail: Alessio.Ishizaka@port.ac.uk
}

\begin{abstract}
Companies are increasingly introducing cloud-based ERP systems as a solution for integrating all-in-one business functions into the Internet. To support this decision, this paper proposes the Group Analytic Hierarchy Process Sorting (GAHPSort) method, which extends the classical AHP for sorting problems with a large number of alternatives. Our study is specifically based on two steps: Firstly, the cloud-based ERP vendors are sorted with GAHPSort into two classes: accepted or rejected. Secondly, a single solution is selected with Analytic Network Process (ANP) among accepted vendors. To validate our model, we present the results obtained from a real case study.
\end{abstract}

Keywords: Cloud ERP, Selection, Sorting problems, Multi-criteria group decision making, GAHPSort, ANP.

\section{Introduction}

Multi-criteria decision analysis (MCDA) methods have been developed to solve choice, sorting, ranking, description, elimination and design problems [1]. Among them, the Analytic Hierarchy Process (AHP) is a useful and widespread method for solving choice and ranking problems [2, 3]. It has been recently adapted to solve sorting problems with AHPSort [4]. This means that alternatives are sorted into predefined ordered 
[Postprint] Please cite as: López C, Ishizaka A, GAHPSort: a new group multi-criteria decision method for sorting a large number of the cloud-based ERP solutions, Computers in Industry, 92, 12-24, 2017

classes, for example good, average and bad classes. This type of classification is not possible with a ranking method. AHPSort allows simultaneous qualitative and quantitative criteria treatment. This means that a table of performance is not needed a priori. Moreover, GAHPSort inherits the advantages of AHP: it has associated consistency measures. Thus, inconsistent answers from participants can be discussed or discarded. Finally, AHPSort requires far less pairwise comparisons than AHP, which facilitates decision making within large scale problems. As most problems are solved by several people (committees, task force, etc.), we further extend AHPSort to group sorting problems with Group Analytic Hierarchy Process Sorting (GAHPSort) in this paper. This new method has been used to select the cloud-based ERP system that best suits the adopter firm's needs.

The cloud computing paradigm has in the last years been propagated in the enterprise systems industry. Nowadays, more and more ERP vendors offer cloud-based systems [5]. Unlike on-premises packages, cloudbased ERP applications do not locate end-users' data and computing resources in the IT infrastructure of the adopter company [6]. These are based on a distribution computing architecture that allows its users to easily access software and associate data in the cloud at any time and regardless of their location [7]. The complexity of the in-house IT infrastructure thus decreases, thereby leading to a reduction in capital expenditure [8]. [9] have found that cloud computing investment significantly increases the firm's market value.

Cloud-based ERP packages are not licensed or owned by the adopter firms. They only pay a monthly fee for the services that they use in the cloud, enabling operative cost savings and a more efficient use of IT resources $[10,11]$. The cloud computing model also provides other benefits to business performance derived from the improved productivity, security, flexibility, and scalability of enterprise IT infrastructure [8, 12-14]. Likewise, it makes the deployment and upgrade of IT-related resources easier, allowing a continuous and agile alignment between the rapidly changing business need of the adopter firm and its operative ERP. 
[Postprint] Please cite as: López C, Ishizaka A, GAHPSort: a new group multi-criteria decision method for sorting a large number of the cloud-based ERP solutions, Computers in Industry, 92, 12-24, 2017

Given the above-mentioned benefits, more and more firms are currently deciding to adopt cloud-based ERP applications. A study of [15] estimates that cloud-based systems accounted for $2 \%$ of the total ERP market by 2011 , although this figure was expected to grow by about $21 \%$ annually through 2015 . In order to attain the expected benefits derived from cloud-based ERP adoption, the selection of the most suitable package from among a large number of options on the market is a critical decision. In fact, a wrong choice can adversely affect the adopter's performance [16, 17].

Selecting a cloud ERP system can be considered more challenging than choosing an on-premise ERP. Cloud ERP services are still new and unfamiliar to firms in comparison with products offered in the mature market of traditional ERP systems. [18] carried out an extensive market analysis of 651 cloud providers for enterprise systems. They point out the lack of transparency in the cloud providers market, which make cloud enterprise system selection more difficult. Some cloud ERP packages do not even provide the advanced functionality of classical ERP systems [19]. In the same line, a recent report reveals companies carry on largely implementing on-premise ERP rather than cloud ERP [20]. This also denotes a lack of understanding of cloud products and the perceived risks of security breaches.

As a result, when a firm decides to adopt a cloud ERP system it is advisable for it to carry out a screening of cloud technology providers. Accordingly, we propose a two-step based selection framework based. In the first step, the most relevant criteria in the evaluation of cloud-based ERP vendors are identified and cloud ERP vendors are screened with GAHPSort. This method provides a comprehensive way to sort cloud ERP providers into different classes, considering multiple conflicting criteria. Moreover, decision makers can establish additional criteria and constraints using the limit profile mechanism. The results enable them to substantially reduce the initial number of alternatives following the company requirements, at the same time as decision makers attain a better understanding of solutions offered by cloud ERP providers. 
[Postprint] Please cite as: López C, Ishizaka A, GAHPSort: a new group multi-criteria decision method for sorting a large number of the cloud-based ERP solutions, Computers in Industry, 92, 12-24, 2017

GAHPSort sorts alternatives, while traditional MCDA methods, such as AHP, TOPSIS or ANP, prioritize them. According to Vetschera [21], "sorting is significantly different from ranking or choice and therefore requires the use of specific methods". Hence, GAHPSort cannot be used alone to select the most appropriate cloud ERP.

In the second step, the cloud-based ERP systems of the qualified vendors are evaluated with ANP (Analytic Network Process (ANP). Saaty provided this as a generalization of AHP [22]. ANP has proven to be an effective instrument for supporting ERP selection process [23-25]. This is specifically very suitable to solve problems when the decision criteria cannot be organized in a unidirectional hierarchical way, by applying a network structure. Furthermore, ANP allows considering feedback between criteria. It has proven to alter the final ranking of ERP alternatives [26]. TOPSIS has also been applied in the ERP selection process [27]. However, this method has the weakness of assigning reliable subjective preferences to the criteria. By contrast, ANP is considered a very valuable mechanism when subjectivity exists. To use this, decision makers evaluate criteria using pairwise comparison. Subsequently, ANP enables estimating the relative importance of the weightings of each criterion considered in the cloud-based ERP system selection process. In addition, it generates a cloud-based ERP systems ranking according to the company's requirements and expectations.

In the following sections, we introduce related works and the theoretical focus upon which this research is grounded. Section 2 introduces the cloud-based ERP systems. Section 3 describes the studies developed for supporting the selection of the accurate ERP system. The technique proposed for sorting cloud ERP vendors is detailed in Section 4. Section 5 presents the case study carried out in order to validate our proposal. Finally, Section 6 provides conclusions as well as possible directions for the development of related works in the future. 
[Postprint] Please cite as: López C, Ishizaka A, GAHPSort: a new group multi-criteria decision method for sorting a large number of the cloud-based ERP solutions, Computers in Industry, 92, 12-24, 2017

\section{Cloud-based ERP systems}

The adoption of advanced technology solutions by companies is taking place at an accelerated pace. Continuous advancement in information technology (IT) has been modifying the ways we do business. This has motivated a transition from an industrial economy to a network economy [28], where companies take part in a hyper-connected world over the Internet [29].

In the last few years, there has been a growing demand for cloud-based technological resources. A report [30] suggests that the share of the cloud-based market will reach $\$ 244$ billion by 2017 , growing by a compound annual rate of $17 \%$. Cloud-based tools are developed, deployed, delivered, used, and maintained as virtualized computing services on the Web [31]. Adopter companies can thus easily access a shared pool of configurable computer resources [32], purchasing only what they need and paying for only what they really use.

Enterprise Resource Planning (ERP) packages are among the most widespread enterprise applications. This is due to these solutions integrating the whole business functions, improving their productivity and operational efficiency [33], providing more accurate information to business decision making, and, finally, improving financial performances $[34,35]$. ERP helps companies to gain or maintain competitive advantages over competitors [36]. Nonetheless, the ERP adoption process is never exempt from challenges and significant hazards [37-40]. In spite of this, numerous companies assume the associated risk and they get the ERP adoption process underway.

The emergence of the cloud computing phenomena is specifically transforming the way ERP solutions are designed, developed, supplied, implemented, updated, maintained, and even paid for. The majority of today's on-premise ERP vendors have expanded their products portfolio with cloud-based ERP solutions, and at the same time new providers have entered into the market [5]. 
[Postprint] Please cite as: López C, Ishizaka A, GAHPSort: a new group multi-criteria decision method for sorting a large number of the cloud-based ERP solutions, Computers in Industry, 92, 12-24, 2017

Firms are increasingly adopting cloud-based ERP solutions to re-invent their enterprise systems, decreasing their complexity and costs derived from hardware, software, upgrades, and IT support, and thereby improving their productivity, scalability, and flexibility and making an agile deployment of services easier [8, 10-14]. Cloud ERP adoption also makes better use of the IT resources available, enabling access to data and services system functionalities.

To achieve the expected results of ERP adoption, it is necessary to choose the package that best suits the firm's requirements [41]. However, no single ERP commercial solutions can meet all business needs and the specific particularities of any adopter firm [17, 26]. Likewise, ERP system selection is a difficult and highly complex undertaking, owing to the great number of ERP vendors and packages available in the market, the limitation in available resources, the continuous improvements and upgrading in IT, the existence of interdependences and incompatibilities between the old and new hardware and software systems, the complexity of the business environment, and decision makers' lack of knowledge and experience for system selection decision making methods $[42,43]$. This has led to the development of numerous studies which support the ERP system selection process in a better and more structured way. The next section examines these studies in detail.

\section{ERP selection studies}

Choosing the most suitable ERP package from among a large number of options in the market is a complex and uncertain process [26]. With this in mind, decision makers with limited money, time, and resources have to consider multiple functional and non-functional criteria of different degrees of importance [42]. The need of supporting this task has encouraged the appearance of many advanced methodologies in the ERP selection context. 
[Postprint] Please cite as: López C, Ishizaka A, GAHPSort: a new group multi-criteria decision method for sorting a large number of the cloud-based ERP solutions, Computers in Industry, 92, 12-24, 2017

Some studies about ERP package selection identify the most commonly used criteria and categorize or prioritize them [44-46]. Others mainly focus their efforts on providing frameworks, methodologies, and techniques to assess the available ERP packages and assist decision makers in their decision process [37, 47, 48].

Several frameworks and stage-based methodologies for the selection of ERP solutions can be found in the literature [49-55]. These studies set out the guidelines or sequence of activities that decision makers should carry out for selecting the right ERP solution [55]. For example, they present a high-level model of the ERP acquisition process, which is made up of six interrelated and iterative processes: planning, information search, selection, evaluation, choice, and negotiations.

In order to automate the process of ERP selection, new applications have also been developed [16, 56-60]. These tools assist decision makers in evaluating criteria and systems proposals, helping them to choose the best commercial ERP system. Multi-criteria decision-making approaches have been widely used to develop these decision support systems [61]. Furthermore, [58] introduce a fuzzy quality function deployment method to determine ERP selection criteria. Under another approach, [56] provide a fuzzy cognitive mapbased tool which allows the assessment of possible scenarios about the ERP package selection process.

Additionally, other studies have proposed the use of diverse techniques for assessing ERP systems on the basis of the company's requirements and expectations $[2,3,60-66]$. With this purpose in mind, [60] provide a fuzzy comprehensive appraisal method for facilitating a group decision process. [66], on the other hand, present a combined method based on the PIRCS process and the SMART multi-attribute analysis to evaluate ERP packages alternatives, while [64] prefer TOPSIS and PROMETHEE to rank them. In the same line, an ANPbased method has also been applied alone $[61,63]$ and later in combination with PROMETHEE [67]. Nevertheless, AHP has been the most commonly used technique for the assessment of ERP solutions [1-5]. 
[Postprint] Please cite as: López C, Ishizaka A, GAHPSort: a new group multi-criteria decision method for sorting a large number of the cloud-based ERP solutions, Computers in Industry, 92, 12-24, 2017

Unfortunately, it is noteworthy that these methods based on pairwise comparisons are very time consuming and consequently can only be used when the number of alternatives is small.

In our case study, many services and functionalities offered by ERP cloud vendors are not well known, and therefore require a more detailed analysis. Accordingly, we preferred to use a two-step analysis, where the first step is a pass or reject decision of the vendor and the second step is a ranking of the ERP system. The additional first step is a typical sorting problem with two classes. As no technique is able to solve a problem having qualitative and quantitative criteria and several decision-makers simultaneously, we developed GAHPSort. The next section describes it.

\section{Sorting methods}

\subsection{Introduction}

Several multi-criteria methods have been proposed to assign actions to predefined classes [68]. We usually distinguish three main families.

The first set of methods, referred to as nominal classification methods, handles classification problems where there is no preference order for the predefined groups; i.e., the relationships are symmetric. Most of these methods are based on the computation of a similarity, indifference, or closeness degree between the actions to be classified and the reference actions or central profiles defining the classes, such as PROAFTN [69], filtering procedures [70], TRINOMFC [71], and CLOSORT [72].

The second family of methods, called the sorting methods, is defined for classification problems where the classes are completely ordered (i.e., there is a complete preference structure from the best to the worst in the groups which are given by the decision maker). In this case, the classes are defined either by limiting profiles or by one or several reference actions (also called central profiles), such as Electre-Tri [73, 74], Electre-Tri-nC [75], FlowSort [76], PromSort [77], Theseus method [78], AHPSort [9], and ELECTRE-SORT [79]. 
[Postprint] Please cite as: López C, Ishizaka A, GAHPSort: a new group multi-criteria decision method for sorting a large number of the cloud-based ERP solutions, Computers in Industry, 92, 12-24, 2017

The third family is the ordered clustering or unsupervised ordered classification methods. These methods focus on the automatic discovering of groups of similar objects within the dataset. The groups, also called clusters, are not predefined. The clusters are such that elements from one cluster are very different (distant) from elements of another cluster. Only a few multi-criteria clustering methods have been proposed [80-82].

FlowSort-GDSS [83] has been the first method developed for group sorting. This method is based on the outranking philosophy. It treats problems where the performance of the alternatives with each criterion is given. In this paper, we propose a new sorting method for group decisions: GAHPSort, an extension based on the AHP methodology. In this kind of problems, the performance table is not known a priori but qualitatively evaluated with pairwise comparisons.

\subsection{GAHPSort}

GAHPSort is a new sorting method used to assign alternatives to predefined classes by a group of decision makers. The classes are defined in an ordinal way based on decision makers' preferences. This means that classes are ordered from the most to the least preferred. GAHPSort is based on 10 steps:

\section{A) Problem definition.}

1) The group of $h$ decision makers $\mathrm{DM}_{s}, S=1, \ldots, h$ agrees on the goal, criteria $c_{j}, j=1, \ldots, m$ and alternatives $a_{k} k=1, \ldots, l$ of the problem.

2) The group of decision makers defines the classes $C_{i}, i=1, \ldots, n$, where $n$ is the number of classes. The classes are ordered and have a label (e.g., excellent, good, medium, bad)

3) Each decision maker $\mathrm{DM}_{s}$ defines the profiles of each class. This can be done with limiting profiles $I p_{i j s}$, which indicates the minimum performance needed for each criterion $j$ to belong to a class $C_{i}$ according to $\mathrm{DM}_{\mathrm{s}}$, or with central profiles $c p_{i j s}$, which is given by a typical example of an element belonging to the class $C_{i}$ for the criterion $j$ according to $\mathrm{DM}_{\mathrm{s}}$. For each decision maker, we need $m \cdot(n-$ 
[Postprint] Please cite as: López C, Ishizaka A, GAHPSort: a new group multi-criteria decision method for sorting a large number of the cloud-based ERP solutions, Computers in Industry, 92, 12-24, 2017

1) limiting profiles or $m \cdot n$ central profiles to define all $n$ classes.

\section{B) Evaluations.}

4) Each decision maker $\mathrm{DM}_{s}$ evaluates pairwise the importance of the criteria $c_{j}$ and derives their weight $w_{j s}$ with the eigenvalue method of the AHP.

$$
A_{s} \cdot \mathbf{w}_{s}=\lambda_{s} \cdot \mathbf{w}_{s}
$$

where $A_{s}$ is the comparison matrix for $\mathrm{DM}_{\mathrm{s}}$

$\mathbf{w}_{\mathrm{s}}$ is the priorities/weights vector for $\mathrm{DM}_{\mathrm{s}}$

$\lambda_{s}$ is the maximal eigenvalue for $\mathrm{DM}_{\mathrm{s}}$

5) Each decision maker $\mathrm{DM}_{\mathrm{s}}$ compares in a pairwise comparison matrix a single alternative $a_{k}$ with each limiting profile $I p_{i j s}$ or central profile $c p_{i j s}$ for each criterion $j$.

6) From the comparison matrices of each decision maker, $\mathrm{DM}_{s}$ derives the local priority $p_{k j s}$ for the alternative $a_{k}$ and the local priority $p_{i j s}$ of the limiting profiles $I p_{i j s}$ or central limiting profiles $c p_{i j s}$ with the eigenvalue method (1).

\section{C) Aggregation.}

7) Aggregate the weighted local priorities for each $D M_{s}$, which provides a global priority $p_{k s}$ for the alternative $a_{k}(2)$ and a global priority $I p_{i s}$ for the limiting profile or $c p_{i s}$ for the central profiles (3).

$$
\begin{aligned}
& p_{k s}=\sum_{j=1}^{m} p_{k j s} \cdot w_{j s} \\
& I p_{i s} \text { or } c p_{i s}=\sum_{j=1}^{m} p_{i j s} \cdot w_{j s}
\end{aligned}
$$

\section{D) Assignment to classes.}

8) For each $D M_{s}$, the comparison of $p_{k s}$ with $I p_{i s}$ or $c p_{i s}$ is used to assign the alternative $a_{k}$ to a class $C_{i}$.

a. Limiting profiles: 
[Postprint] Please cite as: López C, Ishizaka A, GAHPSort: a new group multi-criteria decision method for sorting a large number of the cloud-based ERP solutions, Computers in Industry, 92, 12-24, 2017

If limiting profiles have been defined, the alternative $a_{k}$ is assigned to the class $C_{i}$ which has the $I p_{i s}$ just below the global priority $p_{k s}$ (Figure 1 ).

$$
\begin{aligned}
& p_{k s} \geq I p_{1 s} \quad \Rightarrow \quad a_{k} \in C_{1} \\
& I p_{2 s} \leq p_{k s}<I p_{1 s} \Rightarrow \quad a_{k} \in C_{2}
\end{aligned}
$$

$$
p_{k s}<l p_{n-1 s} \quad \Rightarrow \quad a_{k} \in C_{n}
$$

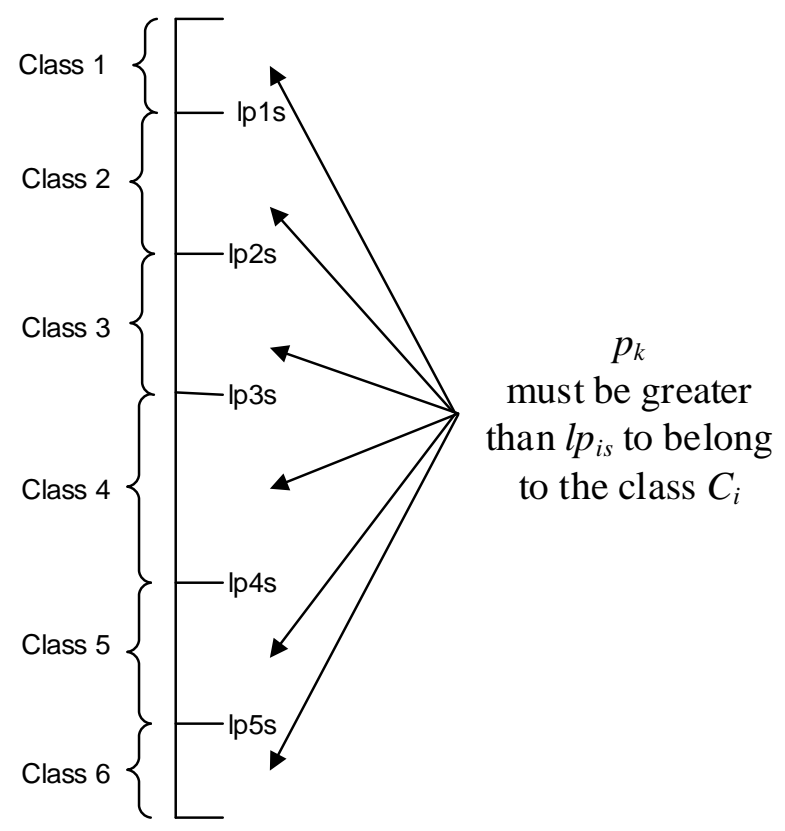

Figure 1. Sorting with limiting profiles

\section{b. Central profiles:}

If the decision maker has difficulties defining a limiting profile, he or she can define a typical example of a class: the central profiles $c p_{i s}$. The limiting profiles are deduced by $\left(c p_{i s}+c p_{i+1 s}\right) / 2$. The alternative $a_{k}$ is assigned to the class $C_{i}$ which has the nearest central profile $c p_{i s}$ to $p_{k s}$ (Figure 2). In the case of 
[Postprint] Please cite as: López C, Ishizaka A, GAHPSort: a new group multi-criteria decision method for sorting a large number of the cloud-based ERP solutions, Computers in Industry, 92, 12-24, 2017

an equal distance between two central profiles, the optimistic assignment vision allocates $a_{k}$ to the upper class, whilst the pessimistic assignment vision allocates $a_{k}$ to the lower class.

$$
\begin{array}{ll}
p_{k s} \geq c p_{1 s} & \Rightarrow a_{k} \in C_{1} \\
c p_{2 s} \leq p_{k s}<c p_{1 s} \text { AND }\left(c p_{1 s}-p_{k s}\right)<\left(c p_{2 s}-p_{k s}\right) & \Rightarrow a_{k} \in C_{1} \\
c p_{2 s} \leq p_{k s}<c p_{1 s} \text { AND }\left(c p_{1 s}-p_{k s}\right)=\left(c p_{2 s}-p_{k s}\right) & \Rightarrow a_{k} \in C_{1} \text { in the optimistic vision } \\
c p_{2 s} \leq p_{k s}<c p_{1 s} \text { AND }\left(c p_{1 s}-p_{k s}\right)=\left(c p_{2 s}-p_{k s}\right) & \Rightarrow a_{k} \in C_{2} \text { in the pessimistic vision } \\
c p_{2 s} \leq p_{k s}<c p_{1 s} \text { AND }\left(c p_{1 s}-p_{k s}\right)>\left(c p_{2 s}-p_{k s}\right) & \Rightarrow a_{k} \in C_{2} \\
\ldots & \\
p_{k s}<c p_{n s} & \Rightarrow a_{k} \in C_{n}
\end{array}
$$

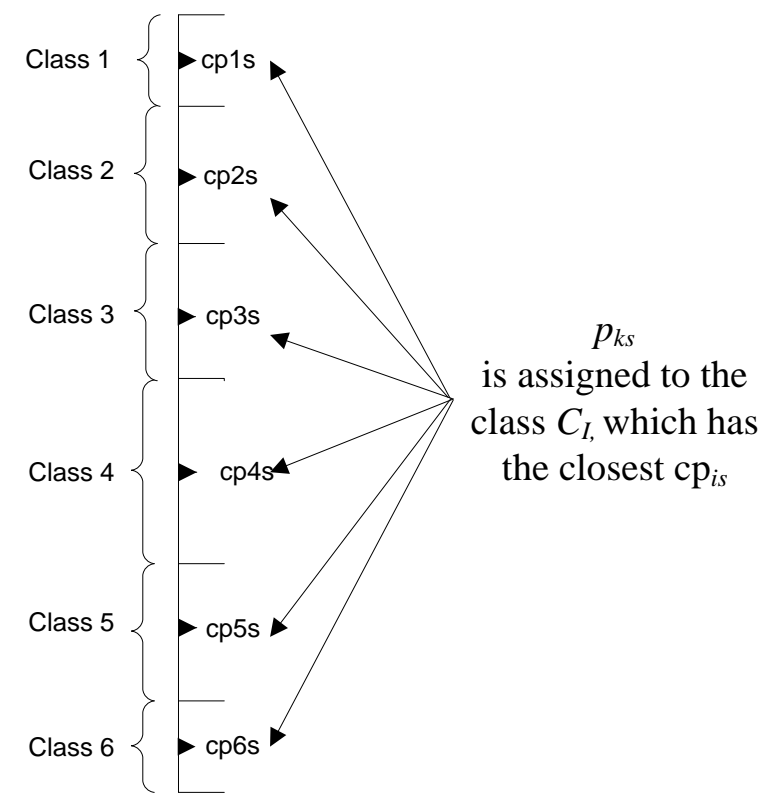

Figure 2. Sorting with central profiles

\section{E) Group aggregation.}

9) There are three scenarios:

a) All $S$ decision makers assign $a_{k}$ to the same class $C_{i}$. Then, $a_{k}$ is unanimously assigned to $C_{i}$. 
[Postprint] Please cite as: López C, Ishizaka A, GAHPSort: a new group multi-criteria decision method for sorting a large number of the cloud-based ERP solutions, Computers in Industry, 92, 12-24, 2017

b) The majority of the decision makers assign $a_{k}$ to the class $C_{i}$. Then, $a_{k}$ is majorly assigned to $C_{i}$.

c) Half of the decision makers assign $a_{k}$ to the class $C_{i}$ and the other half to $C_{i+1}$.

\section{a. Limiting profiles:}

We separate the decision makers into two sets: the set $x$ assigning $a_{k}$ to $C_{i}$ and the set $y$ assigning $a_{k}$ to $C_{i+1}$. Then, we calculate the sum of the distances for the set $x$ between $p_{k s}$ and $I p_{i s}$. Similarly, we calculate the distance for the set $y$ between $p_{k s}$ and $I p_{i s}$. If the sum of the distances is larger for the set $x$, then $a_{k}$ is assigned to $C_{i}$ or otherwise to $C_{i+1}$.

In the case of equal sums, the optimistic assignment vision allocates $a_{k}$ to the upper class, whilst the pessimistic assignment vision allocates $a_{k}$ to the lower class.

$$
\begin{aligned}
& \sum_{s=1, s \in X}^{h}\left(p_{k s}-I p_{i s}\right)>\sum_{s=1, s \in y}^{h}\left(I p_{i s}-p_{k s}\right) \text { then } a_{k} \in C_{i} \\
& \sum_{s=1, s \in X}^{h}\left(p_{k s}-I p_{i s}\right)<\sum_{s=1, s \in y}^{h}\left(I p_{i s}-p_{k s}\right) \text { then } a_{k} \in C_{i+1} \\
& \sum_{s=1, s \in X}^{h}\left(p_{k s}-I p_{i s}\right)=\sum_{s=1, s \in y}^{h}\left(I p_{i s}-p_{k s}\right) \text { then } a_{k} \in C_{i} \text { (in the optimistic vision) } \\
& \sum_{s=1, s \in X}^{h}\left(p_{k s}-I p_{i s}\right)=\sum_{s=1, s \in y}^{h}\left(I p_{i s}-p_{k s}\right) \text { then } a_{k} \in C_{i+1} \text { (in the pessimistic vision) }
\end{aligned}
$$

\section{b. Central profiles:}

We calculate the sum of the distances for all decision makers between $p_{k s}$ and $c p_{\text {is }}$ and between $p_{k s}$ and $c p_{i+1 s}$. If the sum of the distances is smaller between $p_{k s}$ and $c p_{i s}$, then $a_{k}$ is assigned to $C_{i}$ or otherwise to $C_{i+1}$.

$$
\sum_{s=1}^{h}\left|p_{k s}-c p_{i s}\right|<\sum_{s=1}^{h}\left|p_{k s}-c p_{i+1 s}\right| \text { then } a_{k} \in C_{i}
$$


[Postprint] Please cite as: López C, Ishizaka A, GAHPSort: a new group multi-criteria decision method for sorting a large number of the cloud-based ERP solutions, Computers in Industry, 92, 12-24, 2017

$$
\begin{aligned}
& \sum_{s=1}^{h}\left|p_{k s}-c p_{i s}\right|>\sum_{s=1}^{h}\left|p_{k s}-c p_{i+1 s}\right| \text { then } a_{k} \in C_{i+1} \\
& \sum_{s=1}^{h}\left|p_{k s}-c p_{i s}\right|=\sum_{s=1}^{h}\left|p_{k s}-c p_{i+1 s}\right| \text { then } a_{k} \in C_{i} \text { (in the optimistic vision) } \\
& \sum_{s=1}^{h}\left|p_{k s}-c p_{i s}\right|=\sum_{s=1}^{h}\left|p_{k s}-c p_{i+1 s}\right| \text { then } a_{k} \in C_{i+1} \text { (in the pessimistic vision) }
\end{aligned}
$$

10) Repeat processes 5) to 9) for each alternative to be classified.

\subsection{Number of pairwise comparisons}

The high number of comparisons is a well-known problem of AHP [84]. In fact, with / alternatives, $\frac{l \cdot(l-1)}{2}$ pairwise comparisons are necessary for each criterion considered. The increase in the number of comparisons is quadratic. For $m$ criteria, the total number of pairwise comparisons is:

$$
\boldsymbol{m} \cdot \frac{l \cdot(l-1)}{2}
$$

In AHPSort, the number of comparisons is calculated as following. The $b$ limiting or central profiles need first to be compared with each other: $\frac{b \cdot(b-1)}{2}$. Then, the / alternatives are compared to the $b$ profiles. Finally, this is repeated for all $m$ criteria:

$$
m \cdot\left[\frac{b \cdot(b-1)}{2}+(b \cdot l)\right]
$$

The number of comparisons is smaller in AHPSort compared to AHP if the number of alternatives / is much larger than the number of classes, which is normally the case. However, it is to be noted that they are two different methods. AHP is a ranking method and AHPSort is a sorting method. They cannot be interchangeable. 
[Postprint] Please cite as: López C, Ishizaka A, GAHPSort: a new group multi-criteria decision method for sorting a large number of the cloud-based ERP solutions, Computers in Industry, 92, 12-24, 2017

\section{Case study}

The proposed multi-criteria group decision making approach has been applied to a cloud-based ERP system selection in a Spanish firm. This company inspects and controls the appliance of a wide variety of standards and industrial regulations. At the same time, it promotes the region's industrial development.

\subsection{Description of the whole cloud ERP selection process}

The company has decided to adopt a cloud-based ERP system in order to improve the data integration and to operate more efficiently. A team has developed this preliminary study to support the final decision. This study is not described here because it is not the focus of this paper. The team consisted of three decision makers $\left(D M_{s}\right)$ with a wide range of ERP experience and was joined by the authors acting as facilitators for Stages 1 and 2 (Figure 3). They are employees of the case study company. Table 1 introduces the decision makers' profiles. The authors collected the decision preferences and selection criteria of the $\mathrm{DM}_{s}$ to determine the most appropriate cloud-based ERP system for their implementation. The data were collected through personal interviews.

Table 1. Decision makers' profiles

\begin{tabular}{llll}
\hline Characteristics & $\mathbf{D M}_{\mathbf{1}}$ & $\mathbf{D M}_{\mathbf{2}}$ & $\mathbf{D M}_{\mathbf{3}}$ \\
\hline Position & Project manager & IT analyst & IT technician \\
Work experience & 12 years & 12 years & 15 years \\
Industry & Public sector & Public sector & Public sector \\
Familiarity with ERP solutions for & 10 years & 10 years & 15 years \\
Academic background & IT engineer & BA degree & IT engineer \\
\hline
\end{tabular}


[Postprint] Please cite as: López C, Ishizaka A, GAHPSort: a new group multi-criteria decision method for sorting a large number of the cloud-based ERP solutions, Computers in Industry, 92, 12-24, 2017

The full decision workflow process is depicted in Figure 3. There is a great variety of methodologies for selecting the most suitable ERP package described in the literature (Section 3). These should be adapted to the requirements, issue, and individual features of each selection process. Due to the high number of alternatives and criteria, we decided to use a two-stage selection process. The first stage is a prequalification stage where cloud ERP vendors are sorted with GAHPSort into two classes: accepted or rejected. Subsequently, in the second stage, we assessed the cloud ERP solutions provided by the accepted vendors with ANP. Sections 5.1.1 and 5.1.2, respectively, describe both stages.

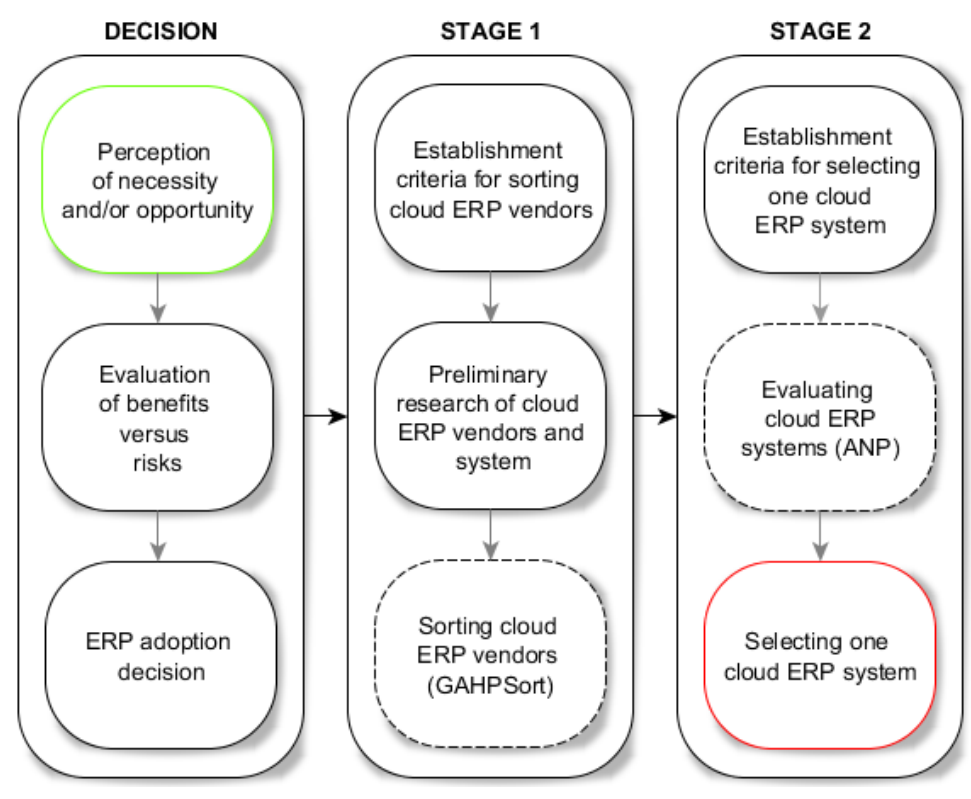

Figure 3. Steps in the cloud ERP system selection

\subsubsection{Stage 1: sorting cloud-based ERP vendors}

One of the most critical points in the selection process is the establishment of the criteria for sorting cloudbased ERP vendors. Indeed, a wrong choice of the ERP vendor would negatively affect the success of the process [22]. In order to support this task, we carried out an extensive literature review of ERP vendor selection criteria. We searched all the databases available to us, which were the ScienceDirect, IEEE-Xplore, Emerald Management Xtra and SpringerLink databases. We applied the following rules in all the searches: 
[Postprint] Please cite as: López C, Ishizaka A, GAHPSort: a new group multi-criteria decision method for sorting a large number of the cloud-based ERP solutions, Computers in Industry, 92, 12-24, 2017

1. The articles have to contain the terms ("ERP" AND "Vendor selection") OR ("Enterprise Resource Planning" AND "Vendor selection") in the title, abstract, keywords or text.

2. The articles have to clearly identify the vendor selection criteria.

3. The articles have to be written in English.

4. The time horizon was not limited to the last 15 years.

Altogether 15 articles were found in the search. Most of the vendor selection criteria are identified by several articles. Hence, we checked them and removed duplicates. The criteria identified were grouped under the same umbrella without changing their initial meaning (e.g., "Maintenance ability" encompasses the following criteria: "Vendor support for maintaining and updating the system", "Maintenance support services", and "Upgrade ability"). The preliminary list was made up of seven criteria. Subsequently, the three decision makers reviewed all the criteria identified. They had the possibility to add or remove criteria not considered relevant for this study. Only one criterion was added and two were removed ("Range of solutions" and "ERP vendor reputation").

Table 2 summarizes the resulting list of criteria used to evaluate the cloud-based ERP vendors. 
[Postprint] Please cite as: López C, Ishizaka A, GAHPSort: a new group multi-criteria decision method for sorting a large number of the cloud-based ERP solutions, Computers in Industry, 92, 12-24, 2017

Table 2. Criterion weighting comparison

\begin{tabular}{lllllc}
\hline Sorting Criterion & \multicolumn{1}{c}{ Source } & $\mathbf{D M}_{1}$ & $\mathbf{D M}_{2}$ & $\mathbf{D M}_{3}$ & Aggregate weight \\
\hline Experience & {$[22,41,43,45,54,64,85]$} & 0.088 & 0.052 & 0.046 & 0.059 \\
Implementation ability & {$[4,59,63,64]$} & 0.220 & 0.194 & 0.181 & 0.199 \\
Maintenance ability & {$[4,21,22,43,55,64]$} & 0.391 & 0.410 & 0.468 & 0.423 \\
Support services & {$[4,22,41,45,49,54,60$,} & 0.227 & 0.274 & 0.215 & \\
& $63,64,66,85]$ & & & & 0.242 \\
Successful outcomes in & {$[54]$} & & & & \\
similar firms & & 0.051 & 0.046 & 0.068 & \\
& & & & & \\
ERP national market share & makers & & & & \\
\hline
\end{tabular}


[Postprint] Please cite as: López C, Ishizaka A, GAHPSort: a new group multi-criteria decision method for sorting a large number of the cloud-based ERP solutions, Computers in Industry, 92, 12-24, 2017

The following step consisted in compiling a list of suitable cloud ERP vendors (i.e., the alternatives). This preliminary research also required the identification of the cloud-based ERP systems supplied by each preselected vendor. To do this, the project team checked diverse sources of information, such as vendors' websites, databases, cloud ERP market reports, and specialized magazines, among others. They initially selected eleven vendors.

In order to sort the cloud-based ERP vendors, we applied a multi-criteria decision-making methodology called GAHPSort, which is described in Section 4.2. Figure 4 shows the elements in the GAHPSort hierarchy. The top level contains the aim of the decision problem. Elements in the middle levels are the criteria defined for sorting the cloud ERP vendors. The third level shows the 11 cloud ERP vendors, which are the alternatives to the problem.

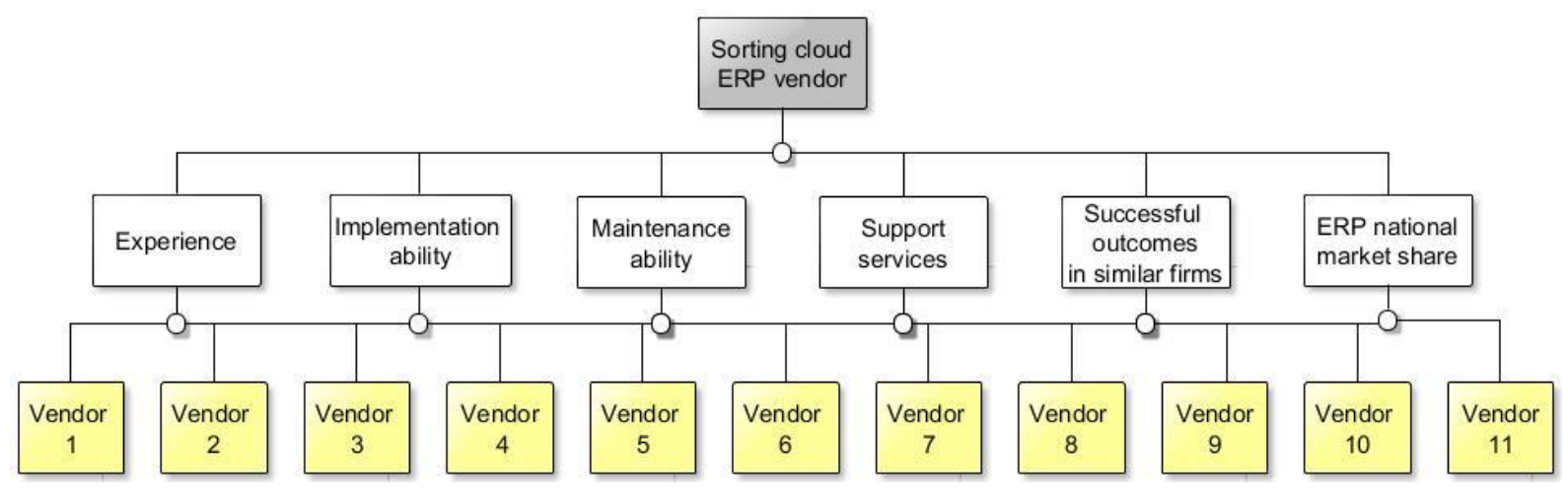

Figure 4. Hierarchical structure to sort ERP vendors

Table 3 shows the limiting profile established by each decision maker. Then, they carried out the criteria pairwise comparisons between each alternative and the limiting profiles in a questionnaire. Appendix A shows an extract. This is based on the widely-accepted nine-point scale which is inspired from the original scale suggested by Saaty (1977). We have adapted each point scale meaning according to the GAHPSort mechanism. Table 4 explains them. Crisp numbers were used to measure the limits and the weights of 
[Postprint] Please cite as: López C, Ishizaka A, GAHPSort: a new group multi-criteria decision method for sorting a large number of the cloud-based ERP solutions, Computers in Industry, 92, 12-24, 2017

criteria. Notwithstanding, these could also be estimated using fuzzy numbers [86]. Yet, as a long debate is open on the validity of Fuzzy AHP [87, 88], we prefer use the traditional crisp numbers.

Table 3. Limiting profiles for each decision maker

\begin{tabular}{|c|c|c|c|c|c|}
\hline \multirow[b]{2}{*}{ Id } & \multirow[b]{2}{*}{ Criteria } & \multirow[b]{2}{*}{ Description } & \multicolumn{3}{|c|}{ Limiting profile } \\
\hline & & & $\mathrm{DM}_{1}$ & $\mathrm{DM}_{2}$ & $\mathrm{DM}_{3}$ \\
\hline Sor1 & Experience & At least .... years in the ICT industry & 10 & 10 & 10 \\
\hline Sor2 & $\begin{array}{l}\text { Implementation } \\
\text { ability }\end{array}$ & Projects do not exceed .... cost limits & $20 \%$ & $10 \%$ & $20 \%$ \\
\hline \multirow[t]{2}{*}{ Sor3 } & $\begin{array}{l}\text { Maintenance } \\
\text { ability }\end{array}$ & $\begin{array}{l}\text { - Basic requests are resolved within .... hours of } \\
\text { receipt }\end{array}$ & 4 & 4 & 3 \\
\hline & & $\begin{array}{l}\text { - Complex requests are resolved within .... days of } \\
\text { receipt }\end{array}$ & 7 & 3 & 3 \\
\hline Sor4 & Support services & Geographic proximity (within a radius of ... $\mathrm{km}$ ). & 200 & 200 & 200 \\
\hline Sor5 & $\begin{array}{l}\text { Successful } \\
\text { outcomes in } \\
\text { similar firms }\end{array}$ & At least successful outcomes in .... sector firm & 1 & 1 & 1 \\
\hline Sor6 & $\begin{array}{l}\text { ERP national } \\
\text { market share }\end{array}$ & At least .... ERP national market share & $5 \%$ & $5 \%$ & $5 \%$ \\
\hline
\end{tabular}

Table 4. GAHPSort 1-9 scale and its meaning

\begin{tabular}{lll}
\hline $\begin{array}{c}\text { Comparison } \\
\text { scale }\end{array}$ & Definition & Explanation \\
\hline 1 & Equal to limit profile & $\begin{array}{l}\text { Alternative } k \text { meets the minimum performance needed to belong } \\
\text { to class } / \text { with limiting profiles } / p i j s \text { for criterion } j\end{array}$ \\
3 & $\begin{array}{l}\text { Weakly over limit } \\
\text { profile }\end{array}$ & $\begin{array}{l}\text { Alternative } k \text { weakly exceeds the minimum performance needed } \\
\text { to belong to class } i \text { with limiting profiles } / p i j s \text { for criterion } j\end{array}$ \\
5 & $\begin{array}{l}\text { Strongly over limit } \\
\text { profile }\end{array}$ & $\begin{array}{l}\text { Alternative } k \text { strongly exceeds the minimum performance needed } \\
\text { to belong to class } i \text { with limiting profiles } / p i j s \text { for criterion } j\end{array}$ \\
7 & Very strongly over & Alternative $k$ very strongly exceeds the minimum performance
\end{tabular}


[Postprint] Please cite as: López C, Ishizaka A, GAHPSort: a new group multi-criteria decision method for sorting a large number of the cloud-based ERP solutions, Computers in Industry, 92, 12-24, 2017

limit profile needed to belong to class $i$ with limiting profiles Ipijs for criterion j

$9 \quad$ Extremely over limit Alternative $k$ extremely exceeds the minimum performance profile needed to belong to class $i$ with limiting profiles Ipijs for criterion j

2, 4, 6, $8 \quad$ Intermediate values

$1 / 2,1 / 3,1 / 4$, Opposite case

$1 / 5,1 / 6,1 / 7$,

$1 / 8,1 / 9$

These intensities are assigned when the alternative $k$ does not exceed the minimum performance needed to belong to class $i$ with limiting profiles Ipijs for criterion $j$

Table 2 also summarizes the weight of the criteria calculated with the eigenvalue method of the AHP. These values indicate the relative importance given to each criterion in the entire sorting exercise. The weights provided by each decision maker are aggregated by taking the average. Maintainability was considered the most important criterion in the assessment of ERP vendors. It achieved a global weight of 0.423 . It is about 2 to 20 times greater than the other criteria. In second place are support services (0.242). These two criteria add up to $66.5 \%$ of the total global weight. Those results underline the company's concern to have a properly maintained ERP system, as evidenced in previous ERP post-implementation studies [89, 90]. The 
[Postprint] Please cite as: López C, Ishizaka A, GAHPSort: a new group multi-criteria decision method for sorting a large number of the cloud-based ERP solutions, Computers in Industry, 92, 12-24, 2017

inconsistency ratio was 0.06 . The maximum accepted upper value for the inconsistency ratio is 0.1 [91], and for that reason the $\mathrm{DM}_{\mathrm{s}}{ }^{\prime}$ answers can be considered as sufficiently consistent.

Then, decision makers compared pairwise each cloud-based ERP vendor with the limiting profile in each criterion in a questionnaire. Once all the comparisons were performed, we computed the priorities of each alternative and limiting profile with Expert Choice. However, as this software is not designed primarily for sorting exercises [92], it requires a file for each cloud-based ERP vendor. Hence, we created a total of 11 files with Expert Choice - one for each alternative. The expertise of the three decision makers is considered equivalent, and they receive the same weight for the overall aggregation of their priorities. Therefore, the overall priority is calculated as an average of the decision makers' priorities.

Table 5 lists the results of the sorting exercise. The 11 ERP vendors were ranked in a descending order according to their overall priority. It is worth noting that the sum of the priorities of the limiting profile(s) and the alternative(s) is always 1 . When we have only two classes, the alternative is in the upper class (accepted) if it has a global priority higher than 0.5 . Figure 5 depicts the results obtained in the cloud-based ERP vendor sorting stage. Seven alternatives reached a higher value compared to the limiting profile score. These cloud-based ERP vendors progressed to the next evaluation stage.

Table 5. Cloud-based ERP vendors' priorities

\section{Priority Priority Priority Overall}

Sor1 Sor2 Sor3 Sor4 Sor5 Sor6 $\quad \mathrm{DM}_{1} \quad \mathrm{DM}_{2} \quad \mathrm{DM}_{3} \quad$ priority


[Postprint] Please cite as: López C, Ishizaka A, GAHPSort: a new group multi-criteria decision method for sorting a large number of the cloud-based ERP solutions, Computers in Industry, 92, 12-24, 2017

\begin{tabular}{ccccccccccc}
\hline Vendor 2 & 0.889 & 0.857 & 0.8 & 0.889 & 0.5 & 0.875 & 0.814 & 0.816 & 0.8 & 0.811 \\
Vendor 1 & 0.9 & 0.875 & 0.5 & 0.889 & 0.5 & 0.875 & 0.660 & 0.655 & 0.626 & 0.647 \\
Vendor 3 & 0.9 & 0.111 & 0.847 & 0.558 & 0.75 & 0.889 & 0.636 & 0.597 & 0.631 & 0.625 \\
Vendor 4 & 0.442 & 0.25 & 0.75 & 0.833 & 0.5 & 0.167 & 0.619 & 0.619 & 0.619 & 0.614 \\
Vendor 5 & 0.9 & 0.1 & 0.879 & 0.152 & 0.875 & 0.9 & 0.534 & 0.532 & 0.586 & 0.548 \\
Vendor 8 & 0.675 & 0.442 & 0.515 & 0.614 & 0.442 & 0.442 & 0.243 & 0.655 & 0.741 & 0.524 \\
Vendor 11 & 0.591 & 0.43 & 0.534 & 0.534 & 0.409 & 0.397 & 0.195 & 0.613 & 0.742 & 0.508 \\
\hline Vendor 10 & 0.558 & 0.442 & 0.442 & 0.519 & 0.454 & 0.409 & 0.192 & 0.443 & 0.803 & 0.468 \\
Vendor 9 & 0.5 & 0.333 & 0.409 & 0.5 & 0.343 & 0.369 & 0.247 & 0.507 & 0.528 & 0.424 \\
Vendor 7 & 0.5 & 0.333 & 0.369 & 0.534 & 0.424 & 0.424 & 0.243 & 0.443 & 0.634 & 0.421 \\
Vendor 6 & 0.386 & 0.442 & 0.386 & 0.442 & 0.386 & 0.369 & 0.227 & 0.670 & 0.395 & 0.412 \\
\hline
\end{tabular}

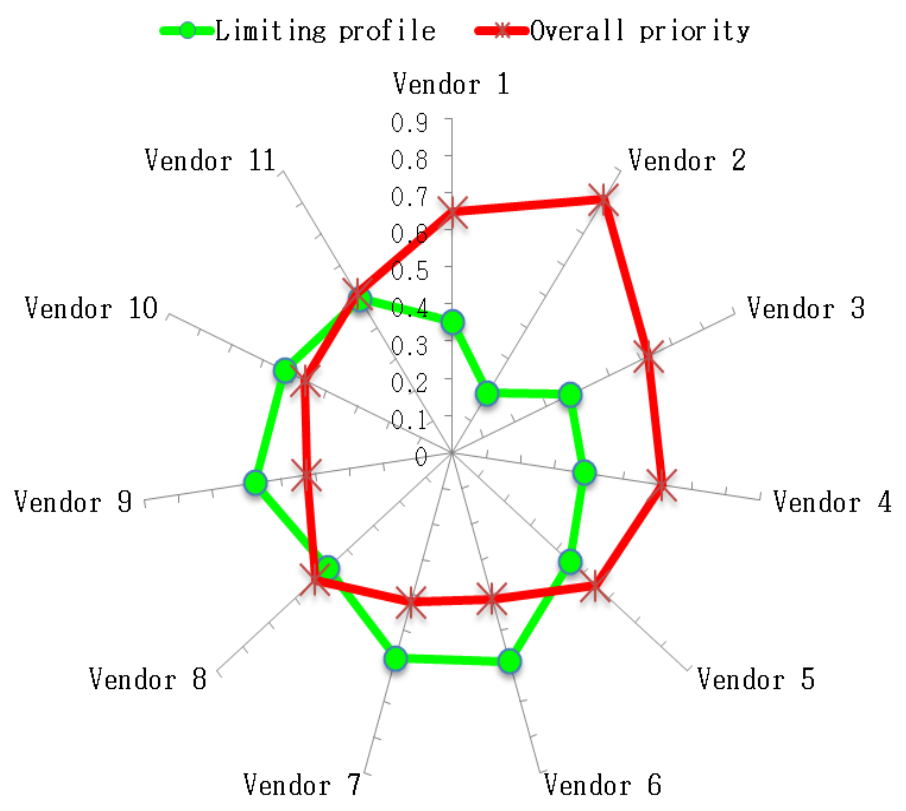

Figure 5. Limiting profile cloud-based ERP vendors radar chart 
[Postprint] Please cite as: López C, Ishizaka A, GAHPSort: a new group multi-criteria decision method for sorting a large number of the cloud-based ERP solutions, Computers in Industry, 92, 12-24, 2017

\subsubsection{Stage 2: selecting the cloud-ERP system}

After the ERP vendors have been qualified in the first sorting stage, the second stage aims to select their commercial package that best meets the company's requirements and expectations.

Our first step was to identify the criteria used in the literature to evaluate the ERP packages by companies. We consulted the same database as Stage 1, but applied the following constraints:

1. The publications have to contain the terms [("ERP" OR "Cloud") AND ("System selection")] OR [(“Enterprise Resource Planning" OR “Cloud") AND ("System selection”)] in the title, abstract, keywords or text.

2. The articles have to identify the ERP system selection criteria clearly.

3. The articles have to be written in English.

4. The time horizon was limited to the last 15 years.

We found 24 articles which identified criteria in the ERP system selection, but only one dealt with cloud ERP packages [50]. This presents a network model made up of six criteria related to system and software quality for evaluating SaaS ERP applications. As in Stage 1, we checked the criteria identified and removed duplicates. The preliminary list contained a total of twenty-four criteria. The group of decision makers checked the criteria identified. They added the criteria "Multilingual", "Monthly cost", "Customization cost" and "Business process reengineering cost". They excluded the criteria "Portability", "Software prestige", "Compatibility with other systems", and "Used by customers and suppliers" because they do not apply to their company. In order to increase their readability, the criteria were grouped into four categories: system, adoption, cost, and time. The full classified list of criteria is given in Table 6.

Table 6. Cloud-based ERP systems evaluation criteria 
[Postprint] Please cite as: López C, Ishizaka A, GAHPSort: a new group multi-criteria decision method for sorting a large number of the cloud-based ERP solutions, Computers in Industry, 92, 12-24, 2017

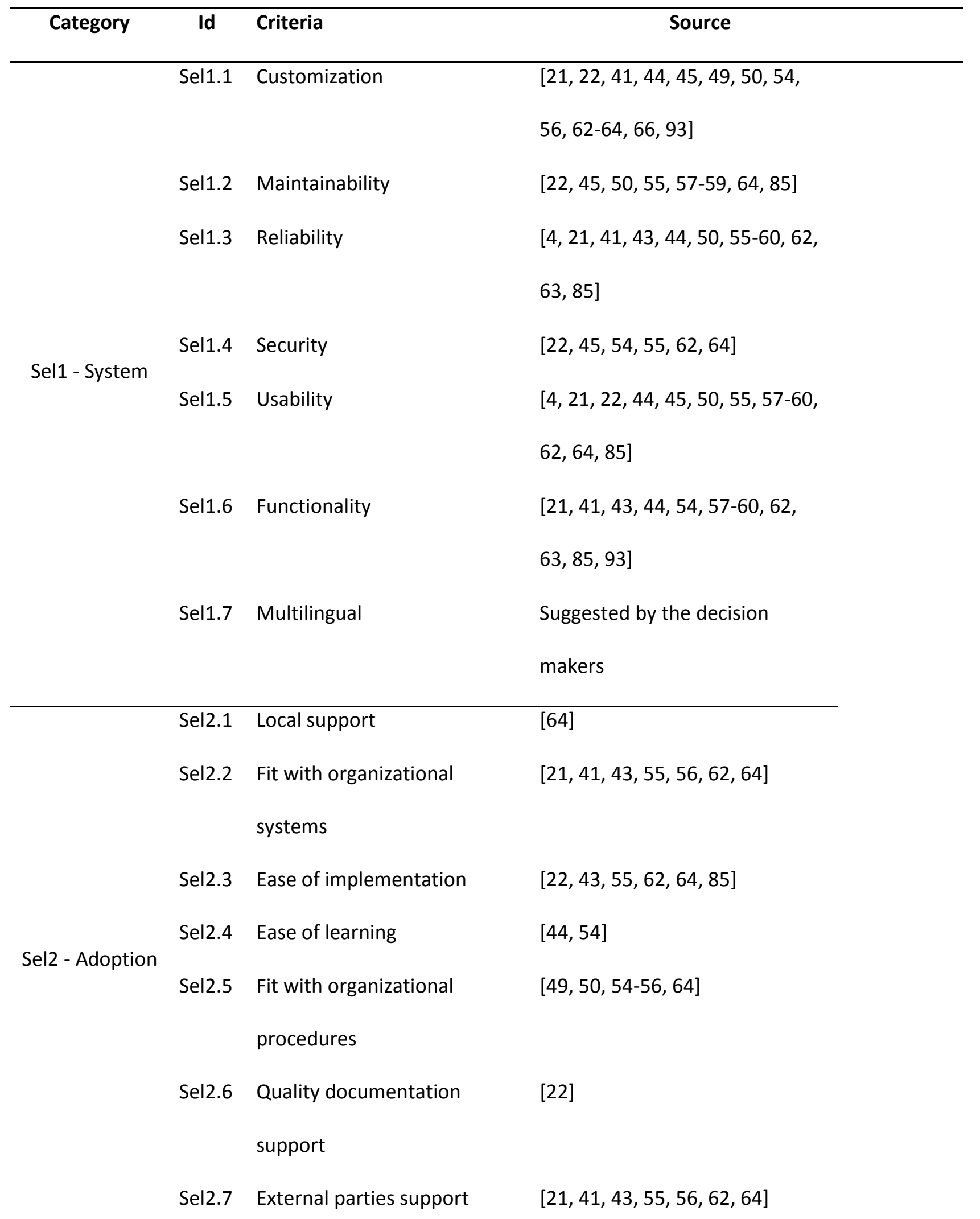


[Postprint] Please cite as: López C, Ishizaka A, GAHPSort: a new group multi-criteria decision method for sorting a large number of the cloud-based ERP solutions, Computers in Industry, 92, 12-24, 2017

Sel3.1 Initial cost

Sel3.2 Training cost

Sel3.3 Monthly cost

Sel3 - Cost Sel3.4 Customization cost

Sel3.5 Upgrading cost

Sel3.6 BPR cost

\section{$[4,21,41,43-45,50,55,56,62$,}

$63,66,85]$

$[41,43-45,56,63,66,85]$

Suggested by the decision

makers

Suggested by the decision

makers

$[4,41,43-45,55,56,62,64,66$,

85]

Suggested by the decision

makers

\section{Sel4.1 Implementation time}

Sel4- Time
$[44,54]$

$[49,50,54-56,64]$

The next step was to evaluate the seven cloud-based ERP solutions issued from the sorting stage. As criteria have independencies, we used the ANP method [94]. Unlike AHP, ANP does not use a hierarchical structure but a network to face a complex decision problem [95]. It represents the problem through the identification of the criteria, sub-criteria, and available alternatives collocated into clusters (Figure 6). 
[Postprint] Please cite as: López C, Ishizaka A, GAHPSort: a new group multi-criteria decision method for sorting a large number of the cloud-based ERP solutions, Computers in Industry, 92, 12-24, 2017

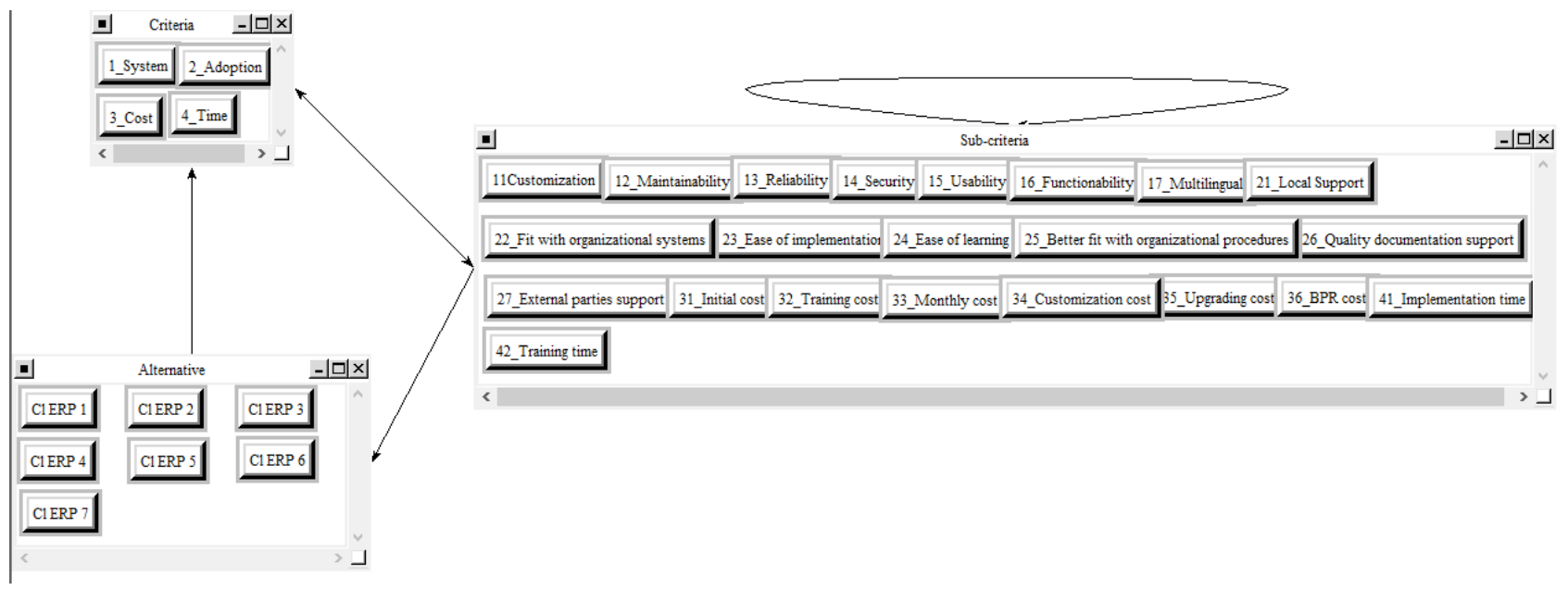

Figure 6. Network structure to select one cloud-based ERP system

As the criteria are not independent, the decision makers marked the dependencies in the influence matrix (Appendix B) where the left column influences the top row. For example, a good customization has a positive influence on a good maintainability, functionality, fit for organizational procedures, customization costs and implementation time.

Following the ANP technique, the elements in a cluster are pairwise compared by assigning evaluations. In order to take into account interdependencies (Appendix B), further questions need to be asked. For example, customization influences maintainability or functionality more and by how much. The decision makers used the nine-point scale suggested by [7] to answer these questions. The whole process can be computed using any mathematical software with some programming function. For our exercise, the Super Decision software was used. The consistency ratio remained below 0.1 for all the matrices. All the decision makers received the same weights, and therefore the aggregate weight is simply given by an average of the scores of the decision makers.

Table 7 shows the weight of the criteria, together with the relative weight of each sub-criterion. The criteria were sorted in a descending order according to their value. "System" is the most important criterion with close to half of the total weight. "Security" is the most important sub-criterion with an aggregate weight of 
[Postprint] Please cite as: López C, Ishizaka A, GAHPSort: a new group multi-criteria decision method for sorting a large number of the cloud-based ERP solutions, Computers in Industry, 92, 12-24, 2017

0.13. This is 1.4 to 16.6 times greater than the weight of the other criteria. This result is in line with previous studies where security has been highlighted as a major concern in cloud computing $[4,96,97]$. The aggregate weights show that the three out of four first sub-criteria belong to the system-related criteria. This is quite understandable, because a cloud-based ERP system not meeting the system requirements will not work properly.

Table 7. Weight of the criteria and sub-criteria

\begin{tabular}{|c|c|c|c|c|c|}
\hline Criteria & Sub-Criteria & $\mathrm{DM}_{1}$ & $\mathrm{DM}_{2}$ & $\mathrm{DM}_{3}$ & Aggregated weight \\
\hline \multirow[t]{8}{*}{ System } & & 0.190 & 0.501 & 0.639 & 0.444 \\
\hline & Customization & 0.005 & 0.019 & 0.018 & 0.014 \\
\hline & Maintainability & 0.006 & 0.065 & 0.039 & 0.037 \\
\hline & Reliability & 0.029 & 0.091 & 0.113 & 0.078 \\
\hline & Security & 0.059 & 0.134 & 0.197 & 0.13 \\
\hline & Usability & 0.032 & 0.109 & 0.110 & 0.084 \\
\hline & Functionality & 0.012 & 0.032 & 0.047 & 0.03 \\
\hline & Multilingual & 0.002 & 0.014 & 0.007 & 0.008 \\
\hline \multirow[t]{7}{*}{ Adoption } & & 0.686 & 0.107 & 0.144 & 0.312 \\
\hline & Local support & 0.041 & 0.004 & 0.006 & 0.017 \\
\hline & Fit with organizational & & & & \\
\hline & systems & 0.179 & 0.004 & 0.008 & 0.064 \\
\hline & Ease of implementation & 0.096 & 0.036 & 0.037 & 0.056 \\
\hline & Ease of learning & 0.046 & 0.065 & 0.065 & 0.059 \\
\hline & Better fit with & 0.107 & 0.005 & 0.012 & 0.041 \\
\hline
\end{tabular}


[Postprint] Please cite as: López C, Ishizaka A, GAHPSort: a new group multi-criteria decision method for sorting a large number of the cloud-based ERP solutions, Computers in Industry, 92, 12-24, 2017

$\begin{array}{lllll}\text { organizational } & & & \\ \text { requirements } & & & \\ \text { Quality documentation } & & & & \\ \text { support } & 0.021 & 0.015 & 0.017 & 0.017 \\ \text { External parties support } & 0.017 & 0.010 & 0.023 & 0.017 \\ & & & & \\ & 0.084 & 0.323 & 0.147 & 0.185 \\ \text { Initial cost } & 0.002 & 0.015 & 0.007 & 0.008 \\ \text { Training cost } & 0.036 & 0.060 & 0.039 & 0.045 \\ \text { Monthly cost } & 0.008 & 0.065 & 0.028 & 0.033 \\ \text { Customization cost } & 0.140 & 0.078 & 0.064 & 0.094 \\ \text { Upgrading cost } & 0.003 & 0.051 & 0.027 & 0.027 \\ \text { BPR cost } & 0.054 & 0.026 & 0.019 & 0.033 \\ & & & & \\ \text { Training time } & 0.040 & \mathbf{0 . 0 6 8} & \mathbf{0 . 0 7 0} & \mathbf{0 . 0 5 9} \\ & & & & \\ \text { Implementation time } & 0.083 & 0.060 & 0.062 & 0.068 \\ & 0.022 & 0.043 & 0.056 & 0.04\end{array}$

Table 8 lists the evaluation results of each decision maker, as well as the overall score and ranking of the seven cloud-based ERP alternatives. All DMs preferred cloud ERP 2. Hence, as shown in Table, the team concluded that the organization should adopt cloud ERP 2.

Table 8. Cloud-based ERP packages ranking

\begin{tabular}{cccccc}
\hline & $\mathrm{DM}_{1}$ Score & $\mathrm{DM}_{2}$ Score & $\mathrm{DM}_{3}$ Score & Overall Score & Overall Ranking \\
\hline Cloud ERP 1 & 0.132 & 0.16 & 0.145 & 0.146 & 4 \\
Cloud ERP2 & 0.277 & 0.257 & 0.238 & 0.257 & 1
\end{tabular}


[Postprint] Please cite as: López C, Ishizaka A, GAHPSort: a new group multi-criteria decision method for sorting a large number of the cloud-based ERP solutions, Computers in Industry, 92, 12-24, 2017

\begin{tabular}{llllll} 
Cloud ERP 3 & 0.168 & 0.162 & 0.194 & 0.175 & 3 \\
Cloud ERP 4 & 0.081 & 0.085 & 0.072 & 0.079 & 7 \\
Cloud ERP 5 & 0.181 & 0.162 & 0.207 & 0.183 & 2 \\
Cloud ERP 6 & 0.081 & 0.09 & 0.073 & 0.081 & 5 \\
Cloud ERP 7 & 0.079 & 0.083 & 0.071 & 0.078 & 6 \\
\hline
\end{tabular}

\section{Discussion}

In our case study, the company had no previous experience in structured decision making, therefore they hired us as facilitators. Their time was also limited and hence they asked us to structure the problem as much we could. For this reason, we compiled in advance a list of criteria. However, we only found one article which is specifically dealing with cloud ERP packages selection [50]. This presents a network model made up of six criteria related to system and software quality for evaluating SaaS ERP applications. These criteria could be applied to both on-premise ERP selection and cloud ERP selection. This confirms that the criteria are very similar. In our study, the DMs added five specific criteria ("Multilingual", "Monthly cost", "Customization cost" and "Business process reengineering cost"). Notwithstanding, the main differences lie in the weight of the criteria.

Depending on the circumstances, there are of course alternative ways to proceed. For example, a steering committee could take part in identifying the cloud ERP system criteria and monitoring the system selection process. In this case, the composition of the participants is very important. The steering committee should bring together a heterogeneous group of participants [98]. This means a group of people who are familiar with the various enterprise system packages but who work in different corporate functions (IT, purchasing, sales, manufacturing, and so on) and represent as much as possible the hierarchy of the company (senior managers, supervisors, general employees, professional employees without supervisory responsibility, etc). 
[Postprint] Please cite as: López C, Ishizaka A, GAHPSort: a new group multi-criteria decision method for sorting a large number of the cloud-based ERP solutions, Computers in Industry, 92, 12-24, 2017

The internal participants are also known as key-users. They outline how the future application should work during the implementation process. Their early and active involvement favors the subsequent training, use and acceptance of the technology when operative [99]. [52] even reveals a higher ERP key-user satisfaction and a greater perceived ERP success. The key-users' role is thus critical to achieve a successful system adoption. The active involvement of competent external expertise has been also observed as a critical factor for getting successful ERP initiatives $[100,101]$. They should prove its added-value and recognized knowledge of the problem, as well as an absence of conflicts of interest.

In order to support the steering committee in the cloud ERP selection, this study highlights the importance of carrying out a screening of cloud technology vendors. In this way, GAHPSort helped the DMs to reduce the initial number of alternatives by following the company requirements in a consensual manner.

During the entire cloud ERP selection process, all the participants' opinions should be considered equally important. This will help to attain consensus decision-making. In our case, the DMs' background clearly influenced the weight given to the different criteria. As Table 7 shows, the system-related criterion is considered the most relevant in the cloud-based ERP selection process and receives a weight 2 to 8 times greater than the other criteria. It is important to note that $\mathrm{DM}_{1}$, who is a project manager, is more concerned with the "Adoption" criterion, whilst $\mathrm{DM}_{2}$ and $\mathrm{DM}_{3}$, the two technical people, considered the "System" criterion to be of high importance. Because of DM1 identifying that criterion in second place, the "System" cluster obtained the greatest aggregated weight in the overall ANP form. This highlights that the ANP approach is appropriate to select an agreed cloud ERP in the second stage.

As previously mentioned, the main differences between on-premise and cloud ERP selection were not reflected in the criteria, but rather in the weight of the criteria. This is revealed when we compare our results with the findings of previous studies about on-premise ERP selection with ANP (i.e., [63]). The aggregate 
[Postprint] Please cite as: López C, Ishizaka A, GAHPSort: a new group multi-criteria decision method for sorting a large number of the cloud-based ERP solutions, Computers in Industry, 92, 12-24, 2017

weight of criteria (Table 7) also indicates a lower relevance of cost criteria and time criteria in cloud ERP selection ERP. These reached the first highest and the fourth highest weights (out of 7) respectively in [63]. In the same line, [102] indicates cloud ERP adoption reduces costs in comparison with on-premise ERP, although they also remark an increase of risks related to the security system and integration. This is also shown in our ANP results (Table 7). Hence, cloud ERP selection requires a more careful analysis of system and adoption criteria.

\section{$\underline{\text { 7. Conclusions }}$}

In order to attain the expected benefits derived from cloud-based ERP adoption, the choice of the most suitable ERP package from among the large number of options on the market is a critical decision. Over the last several decades, on-premise ERP selection has been well-studied in the literature. These advances cannot be extrapolated to cloud ERP selection due to the very distinct technology environment in which they operate. Moreover, cloud ERP market and services are still unfamiliar to companies which requires deeper analysis. Accordingly, our work has presented a combined approach of GAHPSort and ANP for selecting the package that best satisfies the adopter company's requirements and expectations. We have illustrated the applicability of the methodology through a real case study of the cloud-based ERP selection.

The selection process was divided into two stages. The first phase consisted in sorting cloud-based ERP vendor candidates with the new methodology: GAHPSort. This innovative sorting technique is based on AHP concepts and therefore keeps their advantages. Moreover, it makes collaborative decision making easier and, at the same time, it reduces the high number of pairwise comparisons. In addition, GAHPSort allows for defining a limiting profile for each decision maker, which can be of assistance in a screening stage. In our case study, "Maintenance ability" and "Support services" are the most important criteria in the assessment of ERP vendor candidates. 
[Postprint] Please cite as: López C, Ishizaka A, GAHPSort: a new group multi-criteria decision method for sorting a large number of the cloud-based ERP solutions, Computers in Industry, 92, 12-24, 2017

In the second stage, the decision makers evaluated cloud-based ERP packages which progressed from the sorting phase. The multi-criteria decision-making tool ANP was used in order to take into account the interactions between criteria. The findings enabled us to prioritize the solutions and to determine which of the cloud-based ERP alternatives is the best choice. Additionally, the results highlight the main differences between on-premise and cloud ERP selection lie in the weight of the criteria more that the criteria themselves. It was found that the "Systems" criterion is the most important in the cloud-based system evaluation.

The approach proposed in this study can support practitioners' decision making during the entire cloudbased ERP selection process. However, ERP selection is only the first stage of a long process, and several further decisions are needed, such as selecting control procedures [103]. The GAHPSort is a generic method that can be applied in any other sorting process. In future works, we aim to extend the method to cases where there are independences between criteria.

\section{Acknowledgements}

The authors would like to thank the decision makers and their company that allowed us to test our methodology in their cloud-based ERP selection process. 
[Postprint] Please cite as: López C, Ishizaka A, GAHPSort: a new group multi-criteria decision method for sorting a large number of the cloud-based ERP solutions, Computers in Industry, 92, 12-24, 2017

\section{Appendix A. Extract of the GAHPSort questionnaire}

Circle one number per row below using the scale:

$1=$ Equal $3=$ Moderate $5=$ Strong $7=$ Very strong $9=$ Extreme

$2,4,6,8$ are intermediate values

Question 1. Compare the relative performance of cloud ERP Vendor against the experience criteria for the sorting stage.

\begin{tabular}{|l|lllllllllllllllll|l|}
\hline Vendor 1 & 9 & 8 & 7 & 6 & 5 & 4 & 3 & 2 & 1 & 2 & 3 & 4 & 5 & 6 & 7 & 8 & 9 & Limiting profile \\
\hline Vendor 2 & 9 & 8 & 7 & 6 & 5 & 4 & 3 & 2 & 1 & 2 & 3 & 4 & 5 & 6 & 7 & 8 & 9 & Limiting profile \\
\hline Vendor 3 & 9 & 8 & 7 & 6 & 5 & 4 & 3 & 2 & 1 & 2 & 3 & 4 & 5 & 6 & 7 & 8 & 9 & Limiting profile \\
\hline Vendor 4 & 9 & 8 & 7 & 6 & 5 & 4 & 3 & 2 & 1 & 2 & 3 & 4 & 5 & 6 & 7 & 8 & 9 & Limiting profile \\
\hline Vendor 5 & 9 & 8 & 7 & 6 & 5 & 4 & 3 & 2 & 1 & 2 & 3 & 4 & 5 & 6 & 7 & 8 & 9 & Limiting profile \\
\hline Vendor 6 & 9 & 8 & 7 & 6 & 5 & 4 & 3 & 2 & 1 & 2 & 3 & 4 & 5 & 6 & 7 & 8 & 9 & Limiting profile \\
\hline Vendor 7 & 9 & 8 & 7 & 6 & 5 & 4 & 3 & 2 & 1 & 2 & 3 & 4 & 5 & 6 & 7 & 8 & 9 & Limiting profile \\
\hline Vendor 8 & 9 & 8 & 7 & 6 & 5 & 4 & 3 & 2 & 1 & 2 & 3 & 4 & 5 & 6 & 7 & 8 & 9 & Limiting profile \\
\hline Vendor 9 & 9 & 8 & 7 & 6 & 5 & 4 & 3 & 2 & 1 & 2 & 3 & 4 & 5 & 6 & 7 & 8 & 9 & Limiting profile \\
\hline Vendor 10 & 9 & 8 & 7 & 6 & 5 & 4 & 3 & 2 & 1 & 2 & 3 & 4 & 5 & 6 & 7 & 8 & 9 & Limiting profile \\
\hline Vendor 11 & 9 & 8 & 7 & 6 & 5 & 4 & 3 & 2 & 1 & 2 & 3 & 4 & 5 & 6 & 7 & 8 & 9 & Limiting profile \\
\hline
\end{tabular}




\section{Appendix B. Influence matrix}

\begin{tabular}{|c|c|c|c|c|c|c|c|c|c|c|c|c|c|c|c|c|c|c|c|c|c|c|}
\hline & 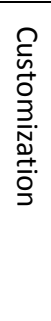 & 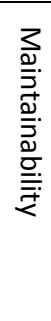 & 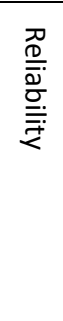 & 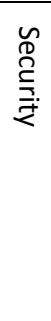 & 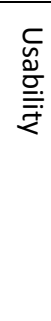 & 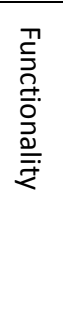 & 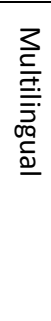 & 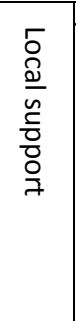 & 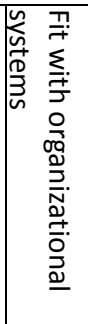 & 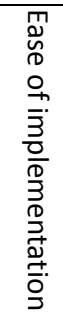 & 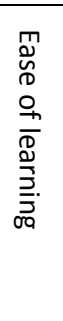 & 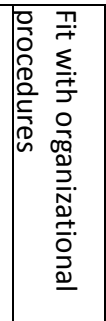 & 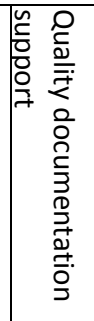 & 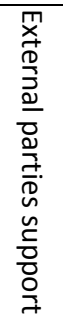 & 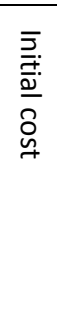 & 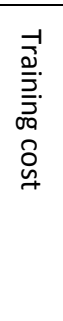 & 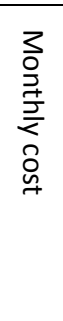 & 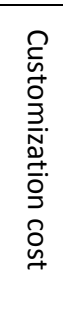 & 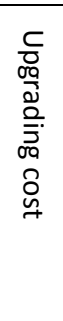 & 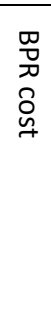 & 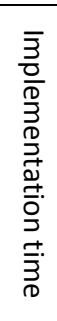 & 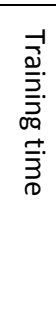 \\
\hline Customization & & $x$ & & & & $\mathrm{X}$ & & & & & & $x$ & & & & & & $\mathrm{X}$ & & & $x$ & \\
\hline Maintainability & & & $x$ & $x$ & $x$ & & & & & & & & & & & & & & & & & \\
\hline Reliability & & & & & $\mathrm{X}$ & & & & & & & & & & & & & & & & & \\
\hline \multicolumn{23}{|l|}{ Security } \\
\hline Usability & & & & & & & & & & & $x$ & & & & & & & & & & & $x$ \\
\hline Functionality & & & & & $\mathrm{x}$ & & & & & & $x$ & & & & & & $\mathrm{X}$ & & & & & $x$ \\
\hline Multilingual & & & & & $\mathrm{x}$ & & & & & & & & & & & & & & & & & \\
\hline Local support & & & & & & & & & & $x$ & & $\mathrm{X}$ & & & & & & & & & $x$ & \\
\hline $\begin{array}{l}\text { Fit with organizational } \\
\text { systems }\end{array}$ & & & & & & & & & & $x$ & & & & & & & & $x$ & & & & \\
\hline Ease of implementation & & & & & & & & & & & & & & & & & & & & & $\mathrm{X}$ & \\
\hline Ease of learning & & & & & & & & & & & & & & & & $x$ & & & & & & $x$ \\
\hline $\begin{array}{l}\text { Fit with organizational } \\
\text { procedures }\end{array}$ & & & & & & & & & & & & & & & & & & & & $x$ & $\mathrm{x}$ & \\
\hline $\begin{array}{l}\text { Quality documentation } \\
\text { support }\end{array}$ & & & & & & & & & & & $x$ & & & & & & & & & & $x$ & $\mathrm{x}$ \\
\hline External parties support & & & & & & & & & & $\mathrm{X}$ & $x$ & & $\mathrm{X}$ & & & & & & & & $\mathrm{x}$ & $\mathrm{x}$ \\
\hline \multicolumn{23}{|l|}{ Initial cost } \\
\hline \multicolumn{23}{|l|}{ Training cost } \\
\hline \multicolumn{23}{|l|}{ Monthly cost } \\
\hline \multicolumn{23}{|l|}{ Customization cost } \\
\hline Upgrading cost & & $x$ & & & & & & & & & & & & & & & & & & & & \\
\hline BPR cost & & & & & & & & & & & & & & & & & & & & & & \\
\hline
\end{tabular}


[Postprint] Please cite as: López C, Ishizaka A, GAHPSort: a new group multi-criteria decision method for sorting a large number of the cloud-based ERP solutions, Computers in Industry, 92, 12-24, 2017

Implementation time

Training time 
[Postprint] Please cite as: López C, Ishizaka A, GAHPSort: a new group multi-criteria decision method for sorting a large number of the cloud-based ERP solutions, Computers in Industry, 92, 12-24, 2017

\section{References}

[1] C. Kahraman, I. Kaya, A fuzzy multicriteria methodology for selection among energy alternatives, Expert Systems with Applications, 37 (2010) 6270-6281.

[2] N. Karaarslan, E. Gundogar, An application for modular capability-based ERP software selection using AHP method, The International Journal of Advanced Manufacturing Technology, 42 (2009) 1025-1033.

[3] Y.-Y. Shih, A Study of ERP Systems Selection via Fuzzy AHP Method, Information Engineering and Electronic Commerce (IEEC), 2010 2nd International Symposium onTernopil, 2010, pp. 1-4.

[4] C. Wei, C.-F. Chien, M.-J. Wang, An AHP-based approach to ERP system selection, International Journal of Production Economics, 96 (2005) 47-62.

[5] S. Parthasarathya, S. Sharma, Determining ERP customization choices using nominal group technique and analytical hierarchy process, Computers in Industry, 65 (2014) 1009-1017.

[6] B. Roy, The optimisation problem formulation: criticism and overstepping, Journal of the Operational Research Society, 32 (1981) 427-436.

[7] T. Saaty, A scaling method for priorities in hierarchical structures, Journal of Mathematical Psychology, 15 (1977) 234-281.

[8] T. Saaty, The Analytic Hierarchy Process, McGraw-Hill, New York, 1980.

[9] A. Ishizaka, P. Nemery, C. Pearman, AHPSort: an AHP based method for sorting problems, International Journal of Production Research, 50 (2012) 4767-4784.

[10] S. Arnesen, Is a Cloud ERP Solution Right for You?, Strategic Finance Magazine, 10 (2013) 45-50.

[11] C. Rong, S. Nguyen, M. Jaatun, Beyond lightning: A survey on security challenges in cloud computing, Computers \& Electrical Engineering, 39 (2013) 47-54.

[12] S. Basu, S. Chakraborty, M. Sharma, Pricing cloud services - the impact of broadband quality, Omega, 50 (2015) 96-114.

[13] S. Lee, S. Park, G. Lim, Using balanced scorecards for the evaluation of "Software-as-a-service", Information \& Management, 50 (2013) 553-561.

[14] I. Son, D. Lee, J.-N. Lee, Y. Chang, Market perception on cloud computing initiatives in organizations: An extended resource-based view, Information \& Management, 51 (2014) 653-669.

[15] S. Marston, Z. Li, S. Bandyopadhyay, J. Zhang, A. Ghalsasi, Cloud computing - The business perspective, Decision Support Systems, 51 (2011) 176-189.

[16] H. Mouratidis, S. Islam, C. Kalloniatis, S. Gritzalis, A framework to support selection of cloud providers based on security and privacy requirements, Journal of Systems and Software, 86 (2013) 2276-2293.

[17] P. Appandairajan, N. Khan, M. Madiajagan, ERP on Cloud: Implementation strategies and challenges, International Conference on Cloud Computing Technologies, Applications and Management (ICCCTAM), 2012Dubai, 2012, pp. 56-59.

[18] H. Erdogmus, Cloud Computing: Does Nirvana Hide behind the Nebula?, Software, IEEE, 26 (2009) 4-6.

[19] X. Xu, From cloud computing to cloud manufacturing, Robotics and Computer-Integrated

Manufacturing, 28 (2012) 75-86.

[20] C. Martens, P. Hamerman, C. Moore, A. Magarie, The State Of ERP In 2011: Customers Have More Options In Spite Of Market Consolidation, 2011.

[21] U. Cebeci, Fuzzy AHP-based decision support system for selecting ERP systems in textile industry by using balanced scorecard, Expert Systems with Applications, 36 (2009) 8900-8909.

[22] W.-H. Tsai, P.-L. Lee, Y.-S. Shen, H.-L. Lin, A comprehensive study of the relationship between enterprise resource planning selection criteria and enterprise resource planning system success, Information \& Management, 49 (2012) 36-46. 
[Postprint] Please cite as: López C, Ishizaka A, GAHPSort: a new group multi-criteria decision method for sorting a large number of the cloud-based ERP solutions, Computers in Industry, 92, 12-24, 2017

[23] J. Repschlaeger, S. Wind, R. Zarnekow, K. Turowski, Selection criteria for software as a service: an explorative analysis of provider requirements BT, 18th Americas Conference on Information Systems, Seattle, 2012, pp. 484-495.

[24] C. Utzig, D. Holland, M. Horvath, M. Manohar, ERP in the cloud. Is it ready? Are you?, in: B. company (Ed.), 2013, pp. http://www.strategyand.pwc.com/media/file/Strategyand ERP-in-the-Cloud.pdf accessed on the 6th Janaury 2017.

[25] Panorama, 2016 report on ERP systems and entreprise software, Panorama consulting solutions, 2017, pp. http://go.panorama-consulting.com/rs/panoramaconsulting/images/2016-ERP-Report.pdf assessed on the 17th January 2017.

[26] R. Vetschera, Y. Chen, K. Hipel, D. Marc Kilgour, Robustness and information levels in case-based multiple criteria sorting, European Journal of Operational Research, 202 (2010) 841-852.

[27] D. Chou, X. Tan, D. Yen, Web technology and supply chain management, Information Management \& Computer Security, 12 (2004) 338-349.

[28] S. Dutta, B. Bilbao-Osorio, The global information technology report 2012. Living a hyperconnected world, World Economic Forum, 2012.

[29] E. Anderson, Forecast Overview: Public Cloud Services, Worldwide, 2013 Update, Gartner report G00248602, 2013.

[30] O. Fitó, J. Guitart, Business-driven management of infrastructure-level risks in Cloud providers, Future Generation Computer Systems, 32 (2014) 41-53.

[31] J. Weinman, Cloudonomics: The Business Value of Cloud Computing, Wiley, Chichester, 2012.

[32] S.-W. Chou, Y.-C. Chang, The implementation factors that influence the ERP (enterprise resource planning) benefits, Decision Support Systems, 46 (2008) 149-157.

[33] E. Galy, M. Sauceda, Post-implementation practices of ERP systems and their relationship to financial performance, Information \& Management, 51 (2014) 310-319.

[34] T. Oliveira, M. Thomas, M. Espadanal, Assessing the determinants of cloud computing adoption: An analysis of the manufacturing and services sectors, Information \& Management, 51 (2014) 497-510.

[35] M. Zhang, A. Lado, Information systems and competitive advantage: a competency-based view, Technovation, 21 (2001) 147-156.

[36] D. Aloini, R. Dulmin, V. Mininno, Risk management in ERP project introduction: Review of the literature, Information \& Management, 44 (2007) 547-567.

[37] K. Dey, B. Clegg, W. Cheffi, Risk management in enterprise resource planning implementation: a new risk assessment framework, Production Planning \& Control, 24 (2011) 1-14.

[38] E. Mu, L. Kirsch, B. Butler, The assimilation of enterprise information system: An interpretation systems perspective, Information \& Management, 52 (2015) 359-370.

[39] C. Sheu, B. Chae, C.-L. Yang, National differences and ERP implementation: issues and challenges, Omega, 32 (2004) $361-371$.

[40] M. Al-Mashari, A. Al-Mudimigh, M. Zairi, Enterprise resource planning: A taxonomy of critical factors, European Journal of Operational Research, 146 (2003) 352-364.

[41] T. Gürbüz, E. Alptekin, G. Işıklar Alptekin, A hybrid MCDM methodology for ERP selection problem with interacting criteria, Decision Support Systems, 54 (2012) 206-214.

[42] H.-Y. Lin, P.-Y. Hsu, G.-J. Sheen, A fuzzy-based decision-making procedure for data warehouse system selection, Expert Systems with Applications, 32 (2007) 939-953.

[43] B. Baki, K. Çakar, Determining the ERP package-selecting criteria, Business Process Management Journal, $11(2005)$ 75-86.

[44] M. Keil, A. Tiwana, Relative importance of evaluation criteria for enterprise systems: a conjoint study, Information Systems Journal, 16 (2006) 237-262. 
[Postprint] Please cite as: López C, Ishizaka A, GAHPSort: a new group multi-criteria decision method for sorting a large number of the cloud-based ERP solutions, Computers in Industry, 92, 12-24, 2017

[45] M. Méxas, O. Quelhas, H. Costa, Prioritization of enterprise resource planning systems criteria: Focusing on construction industry, International Journal of Production Economics, 139 (2012) 340-350.

[46] J. Esteves, V. Bohorquez, An updated ERP systems annotated bibliography: 2001-2005, Communications of the Association for Information Systems, 26 (2007) 386-446.

[47] E. Shehab, M. Sharp, L. Supramaniam, T. Spedding, Enterprise resource planning, Business Process Management Journal, 10 (2004) 359-386.

[48] L. Aversano, M. Tortorella, Quality evaluation of floss projects: Application to ERP systems, Information and Software Technology, 55 (2013) 1260-1276.

[49] E. Karsak, O. Özogul, An integrated decision making approach for ERP system selection, Expert Systems with Applications, 36 (2009) 660-667.

[50] C.-T. Lien, S.-K. Liang, An ERP system selection model with project management viewpoint-A fuzzy multi-criteria decision-making approach, International Journal of the Information Systems for Logistics and Management, 1 (2005) 39-46.

[51] C.-T. Lin, C.-B. Chen, Y.-C. Ting, An ERP model for supplier selection in electronics industry, Expert Systems with Applications, 38 (2011) 1760-1765.

[52] J.-B. Yang, C.-T. Wu, C.-H. Tsai, Selection of an ERP system for a construction firm in Taiwan: A case study, Automation in Construction, 16 (2007) 787-796.

[53] J. Verville, A. Halingten, An investigation of the decision process for selecting an ERP software: the case of ESC, Management Decision, 40 (2002) 206-216.

[54] J. Verville, A. Halingten, A six-stage model of the buying process for ERP software, Industrial Marketing Management, 32 (2003) 585-594.

[55] Z. Ayağ, R. Özdemir, An intelligent approach to ERP software selection through fuzzy ANP, International Journal of Production Research, 45 (2007) 2169-2194.

[56] S. Bueno, J. Salmeron, Fuzzy modeling Enterprise Resource Planning tool selection, Computer Standards \& Interfaces, 30 (2008) 137-147.

[57] J. Park, H.-Y. Jeong, The QoS-based MCDM system for SaaS ERP applications with Social Network, The Journal of Supercomputing, 66 (2013) 614-632.

[58] C. Şen, H. Baraçlı, Fuzzy quality function deployment based methodology for acquiring enterprise software selection requirements, Expert Systems with Applications, 37 (2010) 3415-3426.

[59] C. Şen, H. Baraçlı, S. Şen, H. Başlıgil, An integrated decision support system dealing with qualitative and quantitative objectives for enterprise software selection, Expert Systems with Applications, 36 (2009) 52725283.

[60] G. Hua, X. Xu-song, Fuzzy Comprehensive Appraisal of ERP Selection, International Conference on Electrical and Control Engineering (ICECE), 2010Wuhan, 2010, pp. 2780-2784.

[61] C. Liang, Q. Li, Enterprise information system project selection with regard to BOCR, International Journal of Project Management, 26 (2008) 810-820.

[62] C. Kahraman, A. Beskese, I. Kaya, Selection among ERP outsourcing alternatives using a fuzzy multicriteria decision making methodology, International Journal of Production Research, 48 (2010) 547-566. [63] S. Perçin, Using the ANP approach in selecting and benchmarking ERP systems, Benchmarking: An International Journal, 15 (2008) 630-649.

[64] J. Razmi, M.S. Sangari, A hybrid multi-criteria decision making model for ERP system selection, 4th International Conference on Information and Automation for Sustainability, ICIAFS 2008Colombo, 2008, pp. 489-495.

[65] L. Wei, H. Zhu, Z. Cao, X. Dong, W. Jia, Y. Chen, A. Vasilakos, Security and privacy for storage and computation in cloud computing, Information Sciences, 258 (2014) 371-386. 
[Postprint] Please cite as: López C, Ishizaka A, GAHPSort: a new group multi-criteria decision method for sorting a large number of the cloud-based ERP solutions, Computers in Industry, 92, 12-24, 2017

[66] D. Olson, B. Johansson, R. de Carvalho, A Combined Method for Evaluating Criteria When Selecting ERP Systems, in: C. Møller, S. Chaudhry (Eds.) Re-conceptualizing Enterprise Information Systems, Springer, Berlin, Heidelberg 2012, pp. 64-74.

[67] H. Kilic, S. Zaim, D. Delen, Selecting "The Best" ERP system for SMEs using a combination of ANP and PROMETHEE methods, Expert Systems with Applications, 42 (2015) 2343-2352.

[68] M. Doumpos, C. Zopounidis, Multicriteria decision-aid classification methods, Kluwer Academic Publishers, New York, 2002.

[69] N. Belacel, Multicriteria assignment method PROAFTN: Methodology and medical application, European Journal of Operational Research, 125 (2000) 175-183.

[70] P. Perny, Multicriteria filtering methods based on concordance and non-discordance principles, Annals of Operations Research, 80 (1998) 137-165.

[71] J. Léger, J.-M. Martel, A multicriteria assignment procedure for a nominal sorting problematic, European Journal of Operational Research, 138 (2002) 349-364.

[72] E. Fernandez, J. Navarro, A. Duarte, Multicriteria sorting using a valued preference closeness relation, European Journal of Operational Research, 185 (2008) 673-686.

[73] W. Yu, ELECTRE TRI: Aspects méthodologiques et manuel d'utilisation, Université Paris-Dauphine, 1992, pp. 80.

[74] M. Kadziński, T. Tervonen, J. Figueira, Robust multi-criteria sorting with the outranking preference model and characteristic profiles, Omega, 55 (2015) 126-140.

[75] J. Almeida-Dias, J. Figueira, B. Roy, A multiple criteria sorting method where each category is characterized by several reference actions: The Electre Tri-nC method, European Journal of Operational Research, 217 (2012) 567-579.

[76] P. Nemery, C. Lamboray, FlowSort: a flow-based sorting method with limiting or central profiles, TOP, 16 (2008) 90-113.

[77] C. Araz, I. Ozkarahan, Supplier evaluation and management system for strategic sourcing based on a new multicriteria sorting procedure, International Journal of Production Economics, 106 (2007) 585-606.

[78] E. Fernandez, J. Navarro, A new approach to multi-criteria sorting based on fuzzy outranking relations: The THESEUS method, European Journal of Operational Research, 213 (2011) 405-413.

[79] A. Ishizaka, P. Nemery, Assigning machines to incomparable maintenance strategies with ELECTRE-SORT, Omega, 47 (2014) 45-59.

[80] Y. De Smet, P. Nemery, R. Selvaraj, An exact algorithm for the multicriteria ordered clustering problem, Omega, 40 (2012) 861-869.

[81] P. Meyer, A.-L. Olteanu, Formalizing and solving the problem of clustering in MCDA, European Journal of Operational Research, 227 (2013) 494-502.

[82] C. Rocha, L. Dias, MPOC: an agglomerative algorithm for multicriteria partially ordered clustering, 4OR, 11 (2013) 253-273.

[83] F. Lolli, A. Ishizaka, R. Gamberini, B. Rimini, M. Messori, FlowSort-GDSS - A novel group multi-criteria decision support system for sorting problems with application to FMEA, Expert Systems with Applications, 42 (2015) 6342-6349.

[84] F. Miccoli, A. Ishizaka, Sorting municipalities in Umbria according to the risk of wolf attacks with AHPSort II, Ecological Indicators, 73 (2017) 741-755.

[85] S. Guan, A Study on the Application of AHP and D-S Theory of Evidence to ERP System Selection, 4th International Conference on Wireless Communications, Networking and Mobile Computing, WiCOM '08Dalian, 2008, pp. 1-4.

[86] A. Ishizaka, Comparison of fuzzy logic, AHP, FAHP and hybrid fuzzy AHP for new supplier selection and its performance analysis, International Journal of Integrated Supply Management, 9 (2014) 1-22. 
[Postprint] Please cite as: López C, Ishizaka A, GAHPSort: a new group multi-criteria decision method for sorting a large number of the cloud-based ERP solutions, Computers in Industry, 92, 12-24, 2017

[87] T. Saaty, L. Tran, On the invalidity of fuzzifying numerical judgments in the Analytic Hierarchy Process, Mathematical and Computer Modelling, 46 (2007) 962-975.

[88] K. Zhü, Fuzzy analytic hierarchy process: Fallacy of the popular methods, European Journal of Operational Research, 236 (2014) 209-217.

[89] C. Lopez, J. Salmeron, Dynamic risks modelling in ERP maintenance projects with FCM, Information Sciences, 256 (2014) 25-45.

[90] C. Law, C. Chen, B. Wu, Managing the full ERP life-cycle: Considerations of maintenance and support requirements and IT governance practice as integral elements of the formula for successful ERP adoption, Computers in Industry, 61 (2010) 297-308.

[91] A. Ishizaka, A. Labib, Review of the main developments in the analytic hierarchy process, Expert Systems with Applications, 38 (2011) 14336-14345.

[92] A. Ishizaka, A. Labib, Analytic Hierarchy Process and Expert Choice: benefits and limitations, OR Insight, 22 (2009) 201-220.

[93] D. Reuther, G. Chattopadhyay, Critical factors for enterprise resources planning system selection and implementation projects within small to medium enterprises, Engineering Management Conference, 2004. Proceedings. 2004 IEEE International, 2004, pp. 851-855.

[94] T. Saaty, M. Takizawa, Dependence and Independence: from Linear Hierarchies to Nonlinear Networks, European Journal of Operational Research 26 (1986) 229-237.

[95] A. Ishizaka, V. Pereira, A fair and transparent employee performance management system based on multi-criteria decision analysis and visual techniques, International Journal of Manpower, 37 (2016) 628-659.

[96] M. Ryan, Cloud computing security: The scientific challenge, and a survey of solutions, Journal of Systems and Software, 86 (2013) 2263-2268.

[97] S. Subashini, V. Kavitha, A survey on security issues in service delivery models of cloud computing, Journal of Network and Computer Applications, 34 (2011) 1-11.

[98] T.M. Somers, K.G. Nelson, A taxonomy of players and activities across the ERP project life cycle, Information \& Management, 41 (2004) 257-278.

[99] C. Berchet, G. Habchi, The implementation and deployment of an ERP system: An industrial case study, Computers in Industry, 56 (2005) 588-605.

[100] P. Ifinedo, Impacts of business vision, top management support, and external expertise on ERP success, Business Process Management Journal, 14 (2008) 551-568.

[101] E. Wang, J. Chen, Effects of internal support and consultant quality on the consulting process and ERP system quality, Decision Support Systems, 42 (2006) 1029-1041.

[102] G. Peng, C. Gala, Cloud ERP: a new dilemma to modern organisations? Journal of Computer Information Systems, 54 (2014), 22-30

[103] S.-I. Chang, D. Yen, C. Chang, D. Jan, Internal control framework for a compliant ERP system, Information \& Management, 51 (2014) 187-205. 